\title{
Prenatal diagnosis of Duchenne muscular dystrophy revealed a novel mosaic mutation in Dystrophin gene: a case report
}

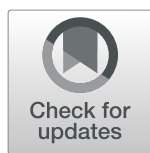

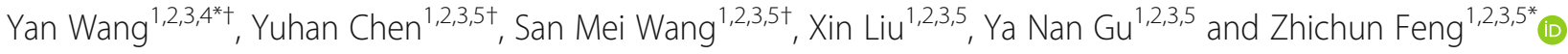

\begin{abstract}
s
Background: Duchenne muscular dystrophies (DMDs) are X-linked recessive neuromuscular disorders with malfunction or absence of the Dystrophin protein. Precise genetic diagnosis is critical for proper planning of patient care and treatment. In this study, we described a Chinese family with mosaic DMD mutations and discussed the best method for prenatal diagnosis and genetic counseling of X-linked familial disorders.

Methods: We investigated all variants of the whole dystrophin gene using multiple DNA samples isolated from the affected family and identified two variants of the DMD gene in a sick boy and two female carriers by targeted next generation sequencing (TNGS), Sanger sequencing, and haplotype analysis.

Results: We identified the hemizygous mutation c.6794delG (p.G2265Efs*6) of DMD in the sick boy, which was inherited from his mother. Unexpectedly, a novel heterozygous mutation c.6796delA (p.I2266Ffs*5) of the same gene, which was considered to be a de novo variant, was detected from his younger sister instead of his mother by Sanger sequencing. However, further NGS analysis of the mother and her amniotic fluid samples revealed that the mother carried a low-level mosaic c.6796delA mutation.

Conclusions: We reported two different mutations of the DMD gene in two siblings, including the novel mutation c.6796delA (p.I2266Ffs*5) inherited from the asymptomatic mosaic-carrier mother. This finding has enriched the knowledge of the pathogenesis of DMD. If no mutation is detected in obligate carriers, the administration of intricate STR/NGS/Sanger analysis will provide new ideas on the prenatal diagnosis of DMD.
\end{abstract}

Keywords: Duchenne muscular dystrophy, Prenatal diagnosis, Dystrophin gene, Next-generation sequencing, Mosaicism

\section{Background}

Duchenne muscular dystrophy (DMD, OMIM \#310200) is a fatal X-linked recessive, inherited neuromuscular disorder characterized by muscle inflammation and progressive deterioration of muscle function [1-3]. The

\footnotetext{
*Correspondence: 001wangyan@sina.com; zhichunfeng81@163.com

†Yan Wang, Yuhan Chen and San Mei Wang contributed equally to this work.

'Department of Clinical Genetics, BaYi Children's Hospital, Seventh Medical Center of Chinese PLA General Hospital, Beijing 100700, China

${ }^{2}$ National Engineering Laboratory for Birth defects prevention and control of key technology, Beijing 100700, China

Full list of author information is available at the end of the article
}

estimated incidence ranges from 10.71 to 27.78 per 100 , 000 males $[4,5]$. Patients with DMD primarily develop muscle weakness between the ages of 2-5 years, during which the symptoms slowly progress and render the patient immobile [6]. The mutation spectrum within the causative gene Dystrophin is complex and varies in types, sizes and locations, resulting in phenotype of different scales $[7,8]$. Considering the devastating effect of this disease and the lack of reliable treatments, early genetic diagnosis and in depth prenatal screening are the main means of reducing the disease incidence as well as of

(c) The Author(s). 2020 Open Access This article is licensed under a Creative Commons Attribution 4.0 International License, which permits use, sharing, adaptation, distribution and reproduction in any medium or format, as long as you give appropriate credit to the original author(s) and the source, provide a link to the Creative Commons licence, and indicate if changes were made. The images or other third party material in this article are included in the article's Creative Commons licence, unless indicated otherwise in a credit line to the material. If material is not included in the article's Creative Commons licence and your intended use is not permitted by statutory regulation or exceeds the permitted use, you will need to obtain permission directly from the copyright holder. To view a copy of this licence, visit http://creativecommons.org/licenses/by/4.0/. The Creative Commons Public Domain Dedication waiver (http://creativecommons.org/publicdomain/zero/1.0/) applies to the data made available in this article, unless otherwise stated in a credit line to the data. 
further reducing alleviate severe permanent sequelae and even death [9].

The classical genetic diagnosis of patients with clinically suspected DMD was conducted through a twostep procedure, including quantitative PCR based multiplex ligation-dependent probe amplification technology (MLPA) [10, 11] and Sanger sequencing [12, 13]. In recent years, benefiting from vast applications of NGS, an increasing number of diseases with mosaic mutations in various causative genes have been identified, such as AKT1 in Proteus syndrome [14], IDH1 in Maffucci syndrome [15], DEPDC5 in cortical dysplasia-associated epilepsy [16] and GNAS in McCune-Albright Syndrome [17]. In this study, we first described the hemizygous mutation c.6794delG in the $D M D$ gene of the proband boy, which was inherited from the mother who carried the heterozygous allele. Then we reported that his sister had heterozygous variant c.6796delA, which was derived from their mother, who was confirmed by NGS to carry a novel mosaic mutation c.6796delA (p.I2266Ffs*5) in the same gene.

\section{Case presentation}

\section{Patient and clinical evaluation}

This study recruited a third-generation Chinese ancestry with 7 years of follow-up (Fig. 1). The genealogical tree is shown in Fig. 2a. Our patient is a 9-year-old Chinese boy (III: 7, Fig. 2a), born in 2003, the first child of healthy parents, who does not have heredity history or consanguineous marriage. He registered to our department of developmental neurology in 2012 with clinical manifestations similar to the phenotypic manifestations of DMD [6] including staggering gait, calf pseudo-hypertrophy, inability to jump along with difficulties in running or climbing, clumsy flat feet, Gowers' sign on rising from floor, and obvious gross motor delay. Laboratory examinations showed significantly increased level of serum Creatine Kinase (CK) $(46,000 \mathrm{U} / \mathrm{L})$. The patient and his family were provided with care advices including neuromuscular management, rehabilitation management, gastrointestinal and nutritional management. In 2018, when his 34-year-old mother was in the second trimester (II: 5), the family visited the Reproductive Medicine Center of our hospital for prenatal consultation. The family history survey informed us that the aunts and uncle of the patient (II: 1, II: 3 and II: 7) shown in Fig. 2a were all married and theiroffsprings are healthy.

Written consent from all guardians of the patient was obtained. Informed consent from all individual participants included in the study was obtained.

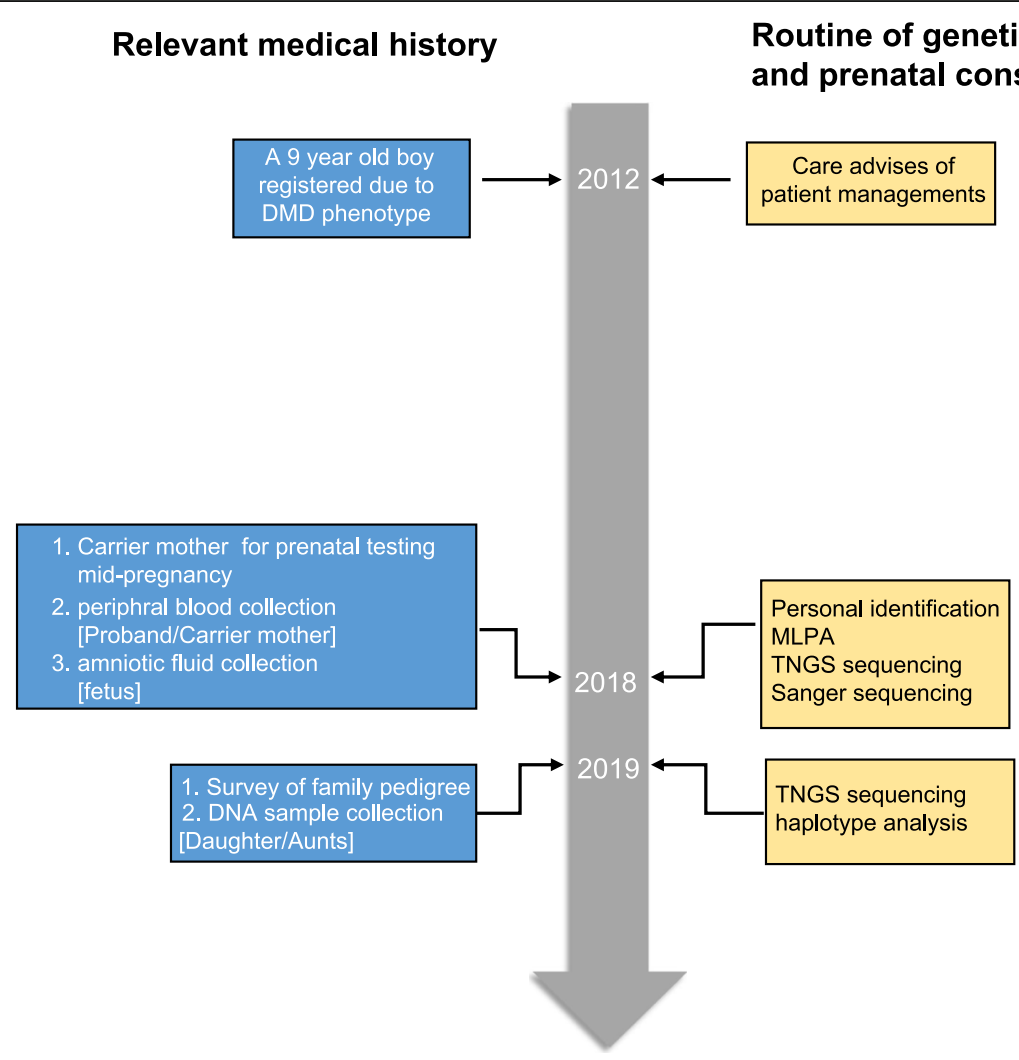

Fig. 1 Summary of the timeline of information reported in this case 
(a)

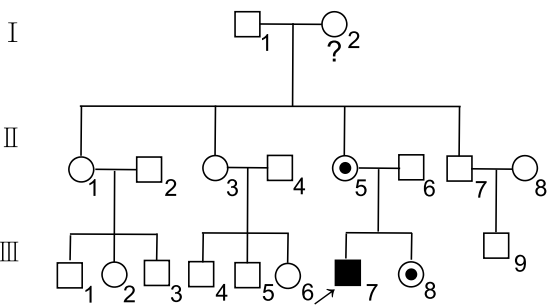

(c)

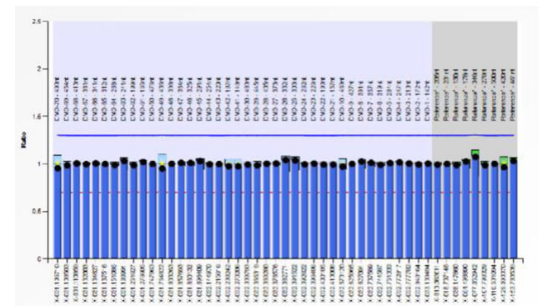

(d)

Proband c. 6794delG

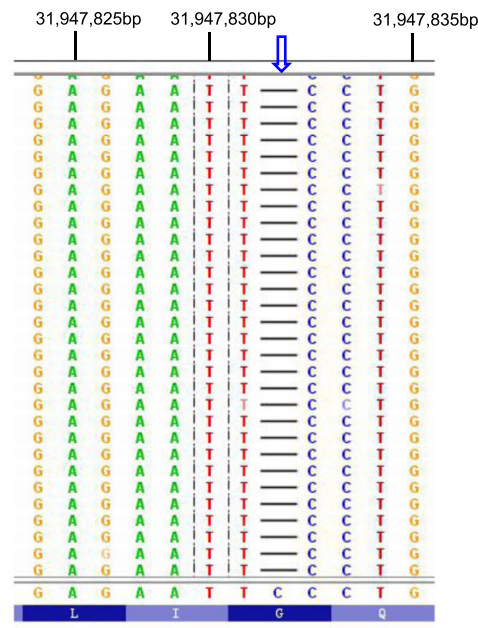

(f)

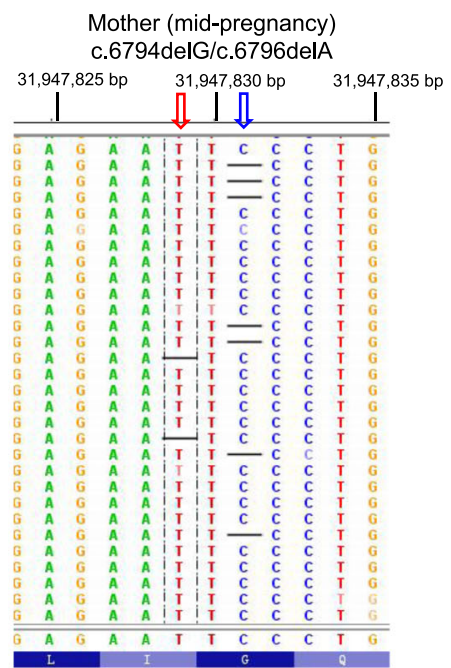

(b)

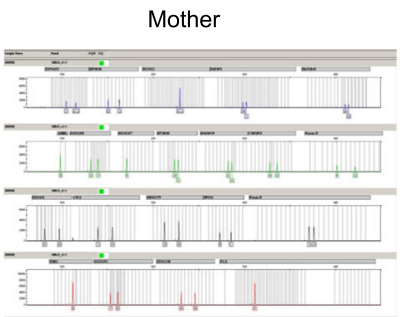

Aminotic Fluid

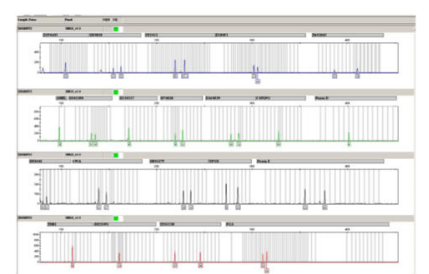

(e)

Aminotic Fluid c. 6796delA

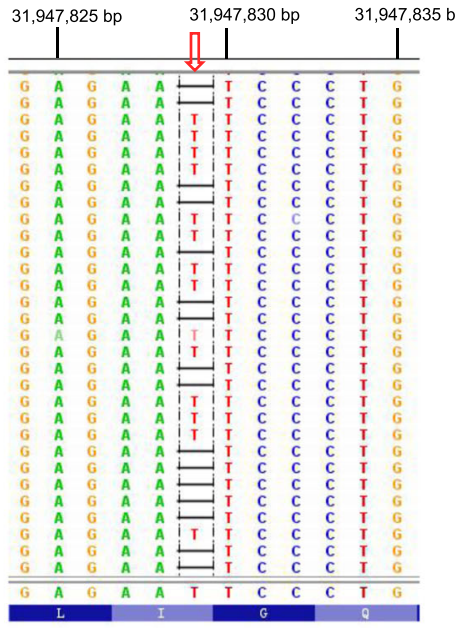

(g)

Mother (post-pregnancy) c.6794delG/c.6796delA

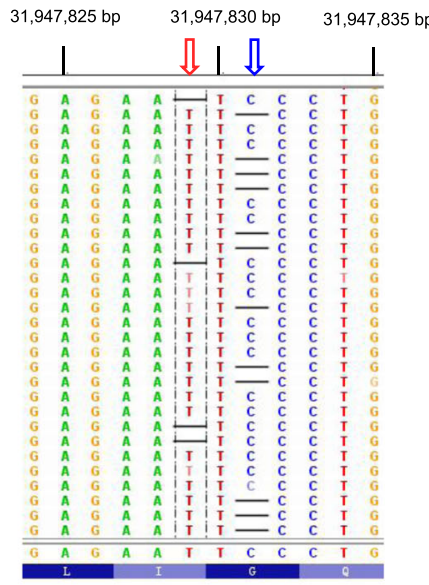

Fig. 2 (See legend on next page.) 
(See figure on previous page.)

Fig. 2 Pedigree of the investigated family and its NGS results of DMD. a Genealogical tree of the DMD family. Proband, male

MD patient; $\square$ : Normal male; $\bigcirc$ : Normal female; $\bullet$ : Female DMD carrier; ? : Female with unknown DMD. b Detection of dystrophin gene mutations by MLPA (c) Detection of maternal components in the amniotic fluid using Microreader 21 Direct ID system. $\mathbf{d}$ The hemizygous mutation c.6794delG was detected in the proband. e The heterozygous c.6796delA was detected in the amniotic fluid. $\mathbf{f}$ The frequency of c.6796delA detected in the mother's peripheral blood during her pregnancy was low, and the mosaic level was 3.87\% (18/465). $\mathbf{g}$ The frequency of c.6796delA detected in the mother's peripheral blood after pregnancy was low, and the mosaic level was 5.31\% (65/1224)

\section{DNA contamination test}

We initiated our study by specimen collection and DNA extraction. We collected $3 \mathrm{ml}$ peripheral blood and mixed it with EDTA-K2 for anticoagulation in designated family members. Hair follicle and oral swabs from the mother were also collected and DNA was extracted from these samples for analysis. Under ultrasound guidance, amniotic membrane puncture was performed to obtain fetal exfoliated cells from the pregnant mother. Total DNA of the indicated samples were extracted using genomic DNA extraction kit according to the procedures in previous publication [18]. The DNA concentrations of different samples were determined using NANODROP $^{\mathrm{mm}} 2000$ instrument (Thermo Fisher Scientific, DE), and then the samples were stored at $-20^{\circ} \mathrm{C}$.

In order to eliminate the contamination of the amniotic fluid by the maternal blood at amniocentesis, DNA samples from the mother (II: 5) and her amniotic fluid (III: 8) were amplified by Microreader 21 Direct ID system (Microread, Suzhou China). It contains 13 combined DNA index system (CODIS) short tandem repeat (STR) loci (CSF1PO, FGA, TH01, TPOX, vWA, D3S1358, D5S818, D7S820, D8S1179, D13S317, D16S539, D18S51, and D21S11), three expanded CODIS STR loci (D12S391, D19S433, and D2S1338), four nonCODIS STR loci (D6S1043, D2S441, Penta D, and Penta $\mathrm{E})$, and one amelogenin locus in one reaction with a four-dye fluorescent (FAM, HEX, ROX and TAMRA) analysis system. From the results in Fig. 2b, no maternal DNA typing was found in the amniotic fluid, indicating that the amniotic fluid was not contaminated by maternal blood and could be used in subsequent tests. The sex chromosomes of the amniotic fluid were $\mathrm{X}, \mathrm{X}$.

Detection of large mutations in dystrophin gene by MLPA In order to determine whether the proband had large rearrangements, MLPA was employed using the SALSA MLPA probe mix P034-A3/P035-A3 DMD/ Becker (MRC Holland, Amsterdam, Netherlands), as previously described [19]. As shown in Fig. 2c, no obvious deletion or duplication was detected. Similar negative results were also obtained from the other family members.

\section{Mutation identification and validation by TNGS and sanger sequencing}

The DNA samples of designated family members and the amniotic fluid were quantified using NANODROP ${ }^{\mathrm{mm}}$ 2000 instrument (Thermo Fisher Scientific, DE). Genomic DNA fragmentation and Library preparation were carried out following the recommendations by Illumina protocols. Sequence capture, enrichment, and elution were performed according to the manufacturer's instructions [20]. The captured fragments were sequenced in pair-end $150 \mathrm{bp}$ mode using the Illumina HiSeq $\mathrm{X}$ ten platform. Real Time Analysis (RTA) software v.1.8.70 (Illumina) was used to analyze the image and obtain the fluorescence intensity in sequences, and the FastQC v0.10.1 program was used to control the data quality. The clean reads were mapped to the UCSC hg19 human reference genome using BWA. The Picard 1.114 tools were used to remove the duplicated reads, and only the unique reads were used for variation detection. Subsequently, GATK Haplotype Caller was used to detect the variants of SNPs and InDels, then GATK Variant Filtration was utilized to filter variants. After the above two steps, data were transformed to VCF format. The variants were first annotated by ANNOVAR and prioritized based on the frequency of variants $(\mathrm{MAF}<0.01)$ in 1000 genome, ESP6500, dbSNP, EXAC, HGMD, and further predicted by SIFT, PolyPhen-2, Mutation Taster, GERP++ and our in-house database.

In the current study, we used NGS to sequence a total of $2.10 \mathrm{MB}$ of the whole Dystrophin gene, including all exons, introns and promoter regions, which can help provide the causative reason for DMD. Thorough NGS, a hemizygous variant was discovered from the proband of DMD (reference transcript: NM_004006.3) with the deletion of a nucleotide $G$ in exon 47, c.6794delG (p.G2265Efs"6) (Fig. 2d). In order to conduct genetic counseling for the second child, DNA was extracted from peripheral blood and amniotic fluid for sequencing. The result of targeted sequencing indicated that the amniotic fluid carried another heterozygous mutation c.6796delA (p.I2266Ffs"5) (Fig. 2e), and a low frequency $(18 / 447,3.87 \%)$ of this mutation was detected in the peripheral blood of the mother in mid-pregnancy (Fig. 2f). When the child was delivered, the c.6796delA 
(p.I2266Ffs*5) mutation was re-examined and the low level of mosaicism $(65 / 1224,5.31 \%)$ was confirmed (Fig. $2 \mathrm{~g})$. It is worth noting the c.6796delA variant has not been reported in any public databases or literature. In addition, according to the American College of Medical Genetics and Genomics (ACMG) interpretation of variants, this variant will result in a truncated protein and is classified as "likely pathogenic". All the high-throughput sequencing results are summarized in Table 1.

Subsequently, the coding variations were validated by Sanger sequencing. PCR amplification products were sequenced by Sangon Biotech Co. Ltd. (Shanghai, China) to analyze the indicated DMD gene mutations in exon 47. The specific primers were designed by Primer Premier 6 (http://www.premierbiosoft.com) and listed in Supplementary Table 1 . According to the family pedigree, the fact that the mother contained both c.6794G heterozygous mutation and a low level of c.6796A mutation of Dystrophin on the same $\mathrm{X}$ chromosome suggested that the mother could be a multi-site mosaicism carrier of DMD. This finding prompted us to further investigate. Importantly, these variants resulted in the frameshift of amino acids 2265 and 2266, respectively. Both mutants are predicted to truncate DMD translation by introducing a termination codon in exon 47 (Fig. 3a). The mutation of the proband c.6794delG (p.G2265Efs*6) resulted in frameshift and a premature stop codon (Fig. 3b). Sequencing of the mother's Dystrophin gene using DNA extracted from peripheral blood revealed that the deletion of a heterozygous variant occurred at the same location (Fig. 3c). At the same time, we found that the amniotic fluid sample (later born as a daughter) carried another frameshift mutation c.6796delA (p.I2266Ffs*5) in exon 47, which was a different heterozygous mutation from the mother and the proband (Fig. 3d). In order to further confirm the hypothesis of mosaicism, hair follicle and oral swab samples of the mother were characterized using Sanger analysis and the results showed that the mutation was c.6794delG. Therefore, considering the NGS data, the possibility of mosaicism was preserved (Fig. 3e). In this case, no mutations of the Dystrophin gene were found from the aunties of the proband (Fig. 3f, representative image of elder aunty). In summary, the low mutation ratio of c.6796A detected by targeted sequencing analysis can be attributed to the low level of mosaicism, which was not easily confirmed by Sanger sequencing.

\section{Determination of the origin of maternal chromosome}

Through the sequence analysis of STR polymorphism and SNP haplotype, we further determined the chromosomal origins of the above two mutations. For STR analysis, primers were selected as described in the previous literature [21], and the detailed information is listed in Fig. 4a. The five informative STRs (DXS9907, STR49, DXS1067, DI623, 3'STR) were decisive for indirect identification of the high-risk haplotype in our case, their locus were located in intron 45 , intron 49 , intron 50 , intron 62 and exon 79, respectively. The pedigree diagram of STR analysis is shown in Fig. 4b. By comparing the fragment size between the proband or amniotic fluid and their mother, we confirmed the maternal origin of the mutants. In addition, we conducted haplotype analysis consisting of 383 SNPs and discovered that the c.6794delG mutant monosomy in the proband and the c.6796delA mutant monosomy in the amniotic fluid were inherited from the same $\mathrm{X}$ chromosome of the mother (6 SNP sites in Fig. 4c and Supplementary Table 2). In short, we successfully identified the pathogenic allele of the mutations.

\section{Discussions and conclusions}

In this study, we discovered a novel frameshift mutation of DMD, c.6796delA, using sequencing method. It is worth noting that the proband carried a c.6794delG mutation in exon 47 of the Dystrophin gene, resulting in a frameshift and a premature stop codon (p.G2265Efs*6), while the amniotic fluid sample (later born as daughter) displayed different mutant site c.6796delA (p.I2266Ffs*5) in the same exon. Unexpectedly, we also identified a low-level mosaicism of the c.6796delA allele from the mother who was already found to carry the c.6794delG heterozygous mutation. Moreover, the fact that the first reported c.6796delA mutation was initially undetected

Table 1 Deep sequencing of the family members in mosaic DMD cases

\begin{tabular}{|c|c|c|c|c|c|c|}
\hline \multirow[t]{3}{*}{ Sample Name } & \multicolumn{6}{|c|}{ Mutant sites } \\
\hline & \multicolumn{3}{|c|}{ ChrX-31,947,831 (c.6794delG) } & \multicolumn{3}{|c|}{ ChrX-31,947,829 (c.6796delA) } \\
\hline & Depth & Frequency (\%) & Result & Depth & Frequency (\%) & Result \\
\hline Proband & $522 / 568$ & 91.90 & Hemi & $2 / 569$ & 0.0 & Non-carrier \\
\hline $\begin{array}{l}\text { Mother carrier } \\
\text { (Pregnancy) }\end{array}$ & $164 / 463$ & 35.32 & Het & $18 / 465$ & 3.87 & $\begin{array}{l}\text { Low level } \\
\text { mosaicism }\end{array}$ \\
\hline Amniotic Fluid & $26 / 1435$ & 0.0 & Non-carrier & $656 / 1446$ & 45.36 & Het \\
\hline $\begin{array}{l}\text { Mother carrier } \\
\text { (Non-pregnancy) }\end{array}$ & $517 / 1229$ & 42.07 & Het & $65 / 1224$ & 5.31 & $\begin{array}{l}\text { Low level } \\
\text { mosaicism }\end{array}$ \\
\hline
\end{tabular}




\section{(a) DNA sequence \\ protein sequence \\ WT TTG CCC CTG CGC CAG GGA ATT CTC AAA CAA TTA \\ LPLRQGILKQL \\ c.6794delG TTG CCC CTG CGC CAG GAA TTC TCA AAC AAT TAA \\ c.6796delA TTG CCC CTG CGC CAG GGA TTC TCAAAC AAT TAA LPLRQGFSNN. \\ LPLRQEFSNN.}

(b)

DMD, c.6794delG

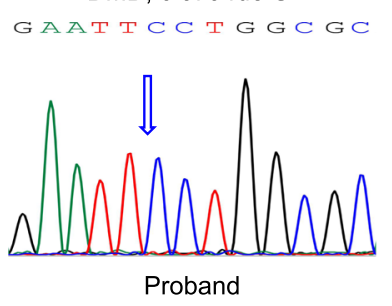

(c)

DMD, c.6794delG

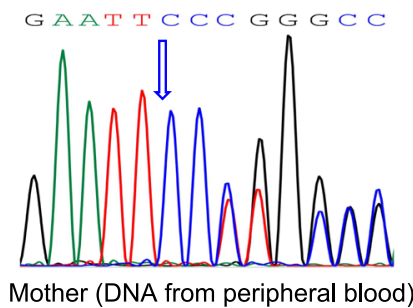

(e)

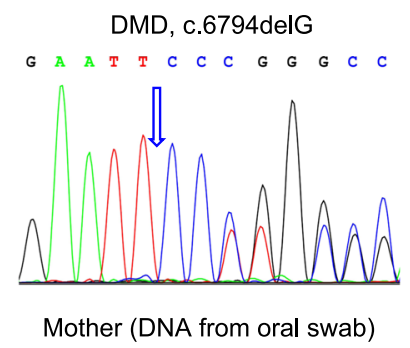

(f) DMD, normal G A A T TC T G G C G

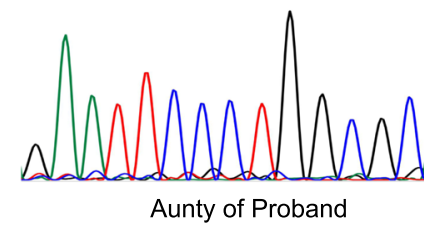

(d)

DMD, c.6796delA

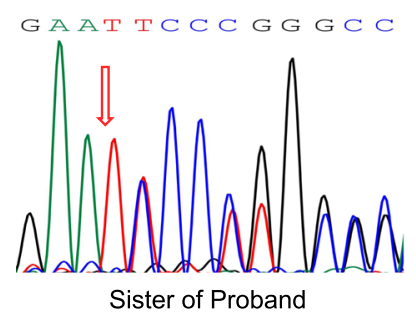

Fig. 3 Sanger analysis for the Dystrophin gene of the designated family members. a Overview of identified mutations. Note that c.6794delG mutant generated a truncated dystrophin protein (p.Gly2265Glu Efs $\times 6$ ), while c.6796delA mutant resulted in a truncated dystrophin protein (p.lle2266phe Efs $\times 5$ ). $\mathbf{b}$-f Confirmation of the mutations by Sanger sequencing from the proband $(\mathbf{b})$, the mother $(\mathbf{c}$, e), the sister of the proband (d), and the aunty of the proband (f). Reference sequence for Dystrophin gene: NM_004006.3

by Sanger sequencing of maternal DNA broadened our horizon of the low-level mosaicism mechanism of this apparent de novo mutation, implying that counseling and prenatal diagnosis for DMD should be conducted in a multi-dimensional and synergistic way.

Considering the complexity and randomness of the mutation spectrum of DMD, numerous diagnostic methods can be used to test DMD mutation, including multiplex PCR [22], multiplex ligation dependent probe amplification (MLPA) [23], array comparative genome hybridization (array CGH) [24], PCR-based Sanger sequencing [25] and real-time PCR sequencing [26]. It is difficult for clinical testing to cover the entire mutational spectrum of DMD on a single platform. The targeted NGS offers a comprehensive, accurate, rapid, and economical method to detect pathogenic mutations in 
(a)

\begin{tabular}{|c|c|c|c|}
\hline \multirow{2}{*}{ Marker } & \multirow{2}{*}{ Locus } & \multirow{2}{*}{ Primer Sequence } & $\begin{array}{l}\text { Predicted } \\
\text { Amplicon }\end{array}$ \\
\hline & & & Size (bp) \\
\hline \multirow{2}{*}{ 3'STR } & \multirow{2}{*}{ Region 3' } & sense: CTGTTTGCGACATTGGCTAT & \multirow{2}{*}{112} \\
\hline & & antiense: GCAAACATCATGGTGATAACTGA & \\
\hline \multirow{2}{*}{ DXS9907 } & \multirow{2}{*}{ Intron 45} & sense: CTGTGGTGTAAGGTTCGCTT & \multirow{2}{*}{203} \\
\hline & & antisense: TAGACTTGACCTCATGGGCT & \\
\hline \multirow{2}{*}{ STR49 } & \multirow{2}{*}{ Intron 49} & sense: CGTTTACCAGCTCAAAATCTCAAC & \multirow{2}{*}{227} \\
\hline & & antisense: CATATGATACGATTCGTGTTTTGC & \\
\hline \multirow{2}{*}{ DXS1067 } & \multirow{2}{*}{ Intron 50} & sense: AAGGTTCCTCCAGTAACAGATTTGG & \multirow{2}{*}{233} \\
\hline & & antisense:TATGCTACATAGTATGTCCTCAGAC & \\
\hline \multirow{2}{*}{ DI623 } & \multirow{2}{*}{ Intron 62} & sense:CGAGACACCCСАССТСTG & \multirow{2}{*}{140} \\
\hline & & antisense: GCCATGGTGAATGATCAGAAA & \\
\hline
\end{tabular}

(b)

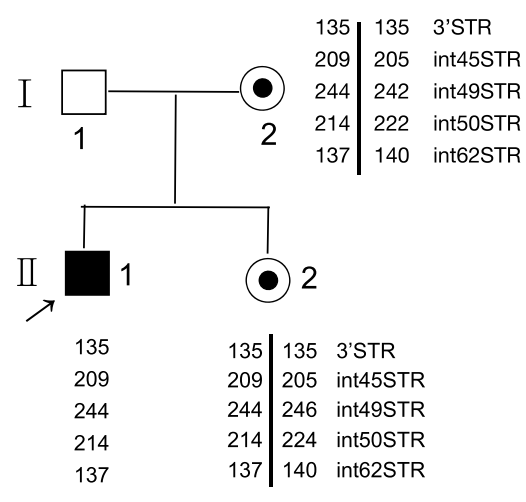

(c)

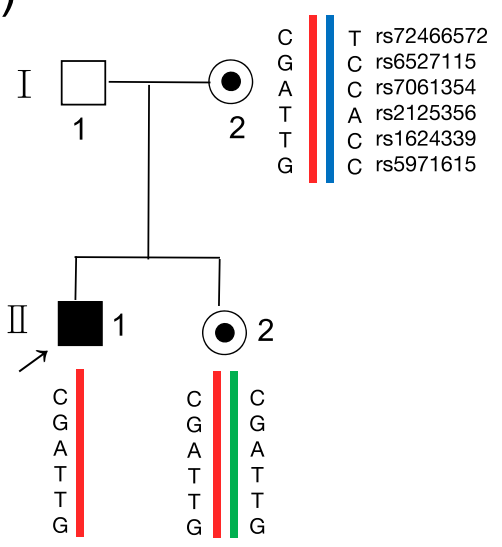

Fig. 4 Chromosome distribution of the two mutations. a Primers for the detection of DMD STR locus. $\mathbf{b}$ STR analysis result in the indicated pedigree. $\mathbf{c}$ The sequencing result of the adjacent representative six SNPs near the mutation regions. Through the linkage genetic analysis using informative STR and SNPS, it was deduced that the mutant allele was inherited from the same chromosome of the mother

DMD, which can help in providing both medical advices to affected family members and prenatal diagnosis for the mother of the proband $[27,28]$.

Importantly, mosaicism is a common but often neglected condition that requires clinicians and geneticists to raise their awareness. Given the high proportion of mosaicism in apparent de novo cases of many genetic disorders, failure to detect mosaicism in carriers could lead to serious consequences, because their next child is at a high risk of carrying the same mutation(s) [29, 30]. Previously, clinical evidences indicated that the higher transmitted rate of risk haplotypes in sporadic DMD cases may originate from female carriers with germinal mosaicism [31, 32].
Therefore, in some cases with de novo mutations, prenatal analysis of the same genes should be considered because of a potential risk of mosaicism. In this study, a parental mutation of c.6794delG was detected in the first child delivered from a female carrier. When carrier became pregnant again, the seemingly high-risk mutation was not detected, but a truly novel fetal mutation site, c.6796delA, emerged, which was further confirmed when the child was born (Fig. 3). The heterozygous mutation c.6796delA found in the mother was identified to have low frequencies of mosaicism during the middle-pregnancy and after the delivery (3.87 and 5.31\%, respectively). Therefore, the identification of germline mosaicism reminds the 
affected families to conduct genetic counseling to understand the recurrence risk of the same disorders [33, 34].

So far, various therapeutic approaches have been extensively developed for DMD [35], most of which are based on the mechanism of complex genetic mutations to complementation or restoration of Dystrophin expression. It is worth noting that the full-length dystrophin protein contains four typical functional domains, including the $\mathrm{N}$ terminal actin-binding Calponin Homology $(\mathrm{CH})$ domain (exon 1-8), the spectrin-rich central Rod domain (exon 9-62), the Cystein Rich domain (exon 63-69), and C-terminal Zinc Finger domain (exon 70-79) (Fig. 5a) [36]. Importantly, there are two genetic hotspots for deletion mutations in the DMD gene, i.e., exons 45-55 and exons 3-7 [23]. These regions account for approximately 60 and $7 \%$ of the total number of reported mutations in DMD, respectively (Fig. 5b) [37, 38]. The remaining mutations involve single nucleotide variants, small deletions or insertions, single-base changes, and splice site changes [4, 39]. Compared to large deletion or duplications, the small insertions or substitutions are less common, and their distribution vary greatly. Interestingly, in the frequently reported cases, the simple insertion or substitution mutations are more likely to resided in different Spectrins repeats within the Central Rod domain (Fig. 5c) [40-42], indicating that the possible significant anchoring or binding functions are important for maintaining the abundance and activity of dystrophy. Indeed, Multiple-polymorphic sites were found within the coding region of DMD and the reduced expression level of dystrophin is associated with the incidence of DMD [43]. Interestingly, the missense mutation c.6794delG has been disclosed in a comprehensive study of DMD patients in South China [44]. In contrary, the novel missense mutation c.6796delA is located in the rod domain and has not been reported in any public variant databases, nor in any chromosome from our in-house database. In summary, all these results suggest that the first reported mutation c.6796delA might be a pathogenic change. In our result, since both mutations are located in the 18th Spectrin region within the Rod domain, the relationships between the mutations and the function of Dystrophin are relatively poor (Fig. $5 \mathrm{~d})$. In the case of incomplete Rod structure, the detailed knowledge of how these frame shifts abolished the PPIs needs further study.

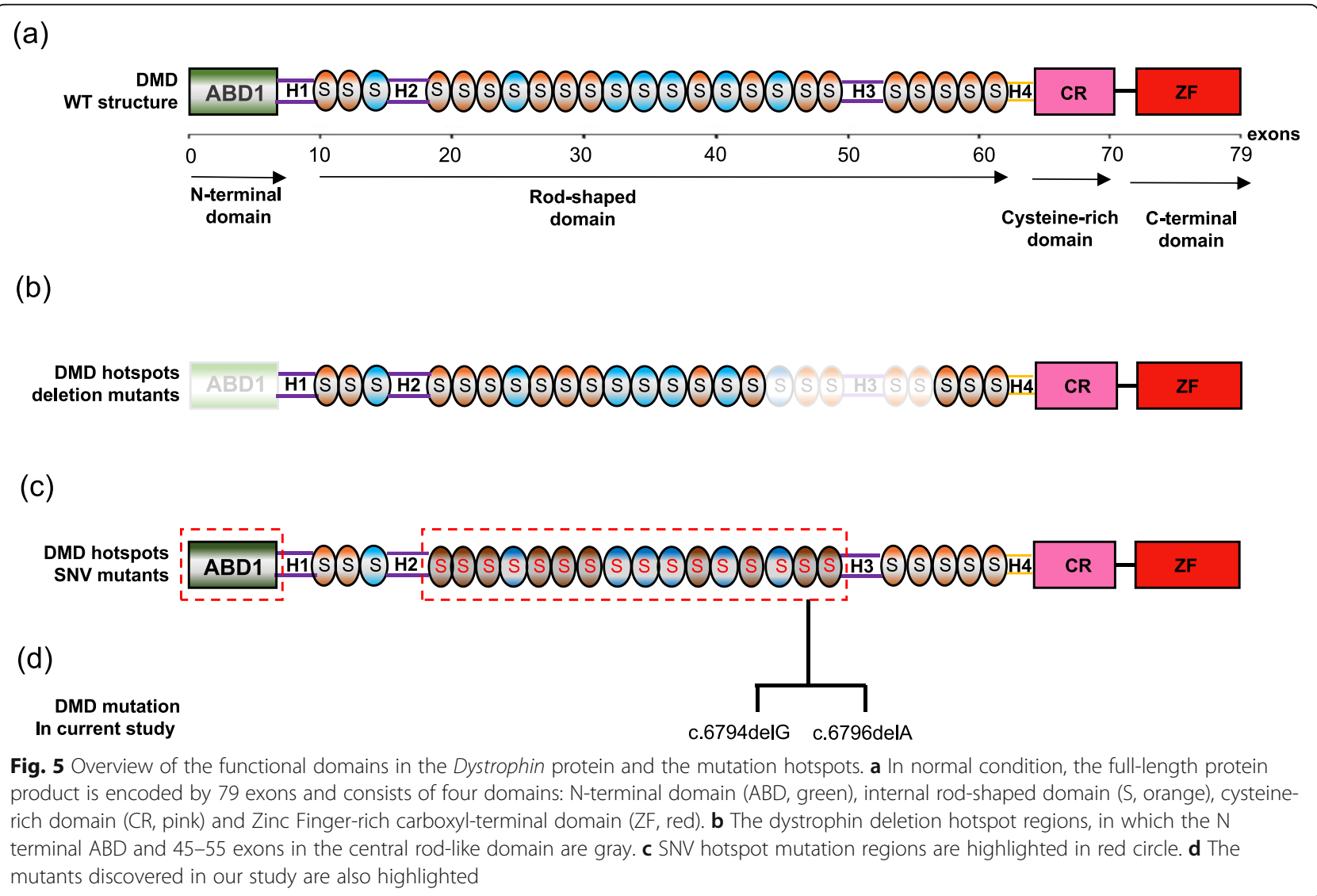


In clinical setting, genetic testing mostly focuses on the proband and the parents. A negative result of mutation in the parents will inevitably lead to a conclusion that the mutation starts from de novo. This tricky issue can be resolved by offering prenatal diagnostic testing for the pregnant woman who needs DMD counseling. Since NGS is the only method which offers the most comprehensive analysis to reliably detect mosaic carriers, prenatal analysis using NGS should be considered, especially in the cases of previously identified de novo mutations.

\section{Supplementary Information}

The online version contains supplementary material available at https://doi. org/10.1186/s12881-020-01157-0.

Additional file 1.

Additional file 2

\section{Abbreviations}

DMD: Duchenne muscular dystrophy; NGS: Next generation sequencing; SNP: Single nucleotide polymorphism; MLPA: Multiplex ligation-dependent probe amplification; STR: Short tandem repeat; AKT1: AKT serine/threonine kinase 1; IDH1: Isocitrate dehydrogenase (NADP(+)) 1 cytosolic; DEPDC5: DEP domain containing 5; GNAS: GNAS complex locus

\section{Acknowledgments}

We thank all the tested individuals, their families and collaborating clinicians for their participation. This study has neither been presented nor submitted or accepted anywhere.

\section{Authors' contributions}

YW and ZCF conceived this study and takes responsibility for the quality of the data. YW and YHC acquired data and played important roles in interpreting the results and writing the manuscript. SMW participated in the patient sample collection and NGS data analysis. XL and YNG performed data analysis. All authors have read and approved the final manuscript.

\section{Funding}

This research was supported by a grant (2017YFC1001700) of the National Key Research and Development Program of China. These funds only supported the cost of reagents for all genetics tests except for STR analysis. They have no role in the design of the study and collection, analysis, and interpretation of data and in drafting or polishing of the manuscript.

\section{Availability of data and materials}

The principal data generated and/or analyzed in this study are included in the published article. The corresponding datasets are available from the corresponding author on request.

\section{Ethics approval and consent to participate}

We ensure that written informed consent acknowledging their voluntary involvement in the current study was obtained from all the patients including the proband and his parents. All procedures performed in studies involving human participants were in accordance with the ethical standards of the Ethical Committee of the Seventh Medical Center of Chinese PLA General Hospital and with the 1964 Helsinki declaration and its later amendments or comparable ethical standards.

\section{Consent for publication}

The parents of the patients provided informed consent to publish this case report, including case description, medical data, and images. Proof of consent to publish from study participants can be requested at any time and a copy of it is available to the journal.

\section{Competing interests}

The authors declare that they have no competing interests.

\section{Author details}

${ }^{1}$ Department of Clinical Genetics, BaYi Children's Hospital, Seventh Medical Center of Chinese PLA General Hospital, Beijing 100700, China. ${ }^{2}$ National Engineering Laboratory for Birth defects prevention and control of key technology, Beijing 100700, China. ${ }^{3}$ Beijing Key Laboratory of Pediatric Organ Failure, Beijing 100700, China. ${ }^{4}$ Clinical Biobank Center, Chinese PLA General Hospital, Beijing 100853, China. ${ }^{5}$ Department of Pediatrics, Chinese PLA General Hospital, Beijing 100700, China.

Received: 18 August 2020 Accepted: 25 October 2020 Published online: 11 November 2020

\section{References}

1. Flanigan KM, Dunn DM, von Niederhausern A, Soltanzadeh P, Gappmaier E, Howard MT, Sampson JB, Mendell JR, Wall C, King WM, et al. Mutational spectrum of DMD mutations in dystrophinopathy patients: application of modern diagnostic techniques to a large cohort. Hum Mutat. 2009;30(12): 1657-66.

2. Koenig M Fau - Hoffman EP, Hoffman Ep Fau - Bertelson CJ, Bertelson Cj Fau - Monaco AP, Monaco Ap Fau - Feener C, Feener C Fau - Kunkel LM, Kunkel LM: Complete cloning of the Duchenne muscular dystrophy (DMD) CDNA and preliminary genomic organization of the DMD gene in normal and affected individuals. Cell. 1987;50(3):509-17. https://doi.org/10.1016/ 0092-8674(87)90504-6.

3. Hoxha M. Duchenne muscular dystrophy: Focus on arachidonic acid metabolites. Biomed Pharmacother. 2019;110:796-802.

4. Mendell JR, Shilling C, Leslie ND, Flanigan KM, al-Dahhak R, Gastier-Foster J, Kneile K, Dunn DM, Duval B, Aoyagi A, et al. Evidence-based path to newborn screening for Duchenne muscular dystrophy. Ann Neurol. 2012; 71(3):304-13.

5. Wein N, Alfano L, Flanigan KM. Genetics and emerging treatments for Duchenne and Becker muscular dystrophy. Pediatr Clin N Am. 2015;62(3): 723-42.

6. Birnkrant DJ, Bushby K, Bann CM, Apkon SD, Blackwell A, Brumbaugh D, Case LE, Clemens PR, Hadjiyannakis S, Pandya S, et al. Diagnosis and management of Duchenne muscular dystrophy, part 1: diagnosis, and neuromuscular, rehabilitation, endocrine, and gastrointestinal and nutritional management. Lancet Neurol. 2018;17(3):251-67.

7. Kwiatkowska J, Slomski R. DMD gene--the largest human gene. Postepy Biochem. 1992:38(2):49-55.

8. van den Bergen JC, Wokke BH, Janson AA, van Duinen SG, Hulsker MA, Ginjaar HB, van Deutekom JC, Aartsma-Rus A, Kan HE, Verschuuren JJ. Dystrophin levels and clinical severity in Becker muscular dystrophy patients. J Neurol Neurosurg Psychiatry. 2014;85(7):747-53.

9. Cheng WL, Hsiao CH, Tseng HW, Lee TP. Noninvasive prenatal diagnosis. Taiwan J Obstet Gynecol. 2015;54(4):343-9.

10. Gatta V, Scarciolla O, Gaspari AR, Palka C, De Angelis MV, Di Muzio A, Guanciali-Franchi P, Calabrese G, Uncini A, Stuppia L. Identification of deletions and duplications of the DMD gene in affected males and carrier females by multiple ligation probe amplification (MLPA). Hum Genet. 2005; 117(1):92-8.

11. Yang J, Li SY, Li YQ, Cao JQ, Feng SW, Wang YY, Zhan YX, Yu CS, Chen F, Li J, et al. MLPA-based genotype-phenotype analysis in 1053 Chinese patients with DMD/BMD. BMC Med Genet. 2013;14(1471-2350 (Electronic)):29.

12. Hamed SA, Hoffman EP. Automated sequence screening of the entire dystrophin CDNA in Duchenne dystrophy: point mutation detection. Am J Med Genet B Neuropsychiatr Genet. 2006;141B(1):44-50.

13. Todorova A, Todorov T, Georgieva B, Lukova M, Guergueltcheva V, Kremensky I, Mitev V. MLPA analysis/complete sequencing of the DMD gene in a group of Bulgarian Duchenne/Becker muscular dystrophy patients. Neuromuscul Disord. 2008;18(8):667-70.

14. Lindhurst MJ, Sapp JC, Teer JK, Johnston JJ, Finn EM, Peters K, Turner J, Cannons $J$, Bick D, Blakemore $L$, et al. A mosaic activating mutation in AKT1 associated with the Proteus syndrome. N Engl J Med. 2011;365(7): 611-9.

15. Amary MF, Damato S, Halai D, Eskandarpour M, Berisha F, Bonar F, McCarthy S, Fantin VR, Straley KS, Lobo S, et al. Ollier disease and Maffucci syndrome 
are caused by somatic mosaic mutations of IDH1 and IDH2. Nat Genet. 2011;43(12):1262-5.

16. Ribierre T, Deleuze C, Bacq A, Baldassari S, Marsan E, Chipaux M, Muraca G, Roussel D, Navarro V, Leguern E, et al. Second-hit mosaic mutation in mTORC1 repressor DEPDC5 causes focal cortical dysplasia-associated epilepsy. J Clin Invest. 2018;128(6):2452-8.

17. Romanet P, Philibert P, Fina F, Cuny T, Roche C, Ouafik L, Paris F, Reynaud R, Barlier A. Using Digital Droplet Polymerase Chain Reaction to Detect the Mosaic GNAS Mutations in Whole Blood DNA or Circulating Cell-Free DNA in Fibrous Dysplasia and McCune-Albright Syndrome. J Pediatr. 2019;205: 281-285.e284

18. Peng $W$, Ma XW, Yang $X$, Zhang WQ, Yan L, Wang YX, Liu X, Wang Y, Feng ZC. Two novel $\mathrm{L} 2 \mathrm{HGDH}$ mutations identified in a rare Chinese family with $\mathrm{L}$ 2-hydroxyglutaric aciduria. BMC Med Genet. 2018;19(1):167.

19. Wang $H, X u$ Y, Liu X, Wang L, Jiang W, Xiao B, Wei W, Chen Y, Ye W, Ji X. Prenatal diagnosis of Duchenne muscular dystrophy in 131 Chinese families with dystrophinopathy. Prenat Diagn. 2017;37(4):356-64.

20. Wang Y, Yang Y, Liu J, Chen XC, Liu X, Wang CZ, He XY. Whole dystrophin gene analysis by next-generation sequencing: a comprehensive genetic diagnosis of Duchenne and Becker muscular dystrophy. Mol Gen Genomics. 2014:289(5):1013-21.

21. Anaya-Segura MA, Rangel-Villalobos H, Martinez-Cortes G, Gomez-Diaz B, Coral-Vazquez RM, Zamora-Gonzalez EO, Garcia S, Lopez-Hernandez LB. Serum Levels of MicroRNA-206 and Novel Mini-STR Assays for Carrier Detection in Duchenne Muscular Dystrophy. Int J Mol Sci. 2016;17(8):1334. https://doi.org/10.3390/ijms17081334.

22. Madania A, Zarzour H, Jarjour RA, Ghoury I. Combination of conventional multiplex PCR and quantitative real-time PCR detects large rearrangements in the dystrophin gene in 59\% of Syrian DMD/BMD patients. Clin Biochem. 2010:43(10-11):836-42.

23. Deepha S, Vengalil S, Preethish-Kumar V, Polavarapu K, Nalini A, Gayathri N, Purushottam M. MLPA identification of dystrophin mutations and in silico evaluation of the predicted protein in dystrophinopathy cases from India. BMC Med Genet. 2017;18(1):67.

24. Marquis-Nicholson R, Lai D, Lan CC, Love JM, Love DR. A streamlined protocol for molecular testing of the DMD gene within a diagnostic laboratory: a combination of Array comparative genomic hybridization and bidirectional sequence analysis. ISRN neurology. 2013;2013:908317.

25. Chen WJ, Lin QF, Zhang QJ, He J, Liu XY, Lin MT, Murong SX, Liou CW, Wang N. Molecular analysis of the dystrophin gene in 407 Chinese patients with Duchenne/Becker muscular dystrophy by the combination of multiplex ligation-dependent probe amplification and sanger sequencing. Clin Chim Acta. 2013:423:35-8

26. Xu Y, Li Y, Song T, Guo F, Zheng J, Xu H, Yan F, Cheng L, Li C, Chen B, et al. A retrospective analysis of 237 Chinese families with Duchenne muscular dystrophy history and strategies of prenatal diagnosis. J Clin Lab Anal. 2018; 32(7):e22445.

27. Barseghyan $H$, Tang W, Wang RT, Almalvez M, Segura E, Bramble MS, Lipson A, Douine ED, Lee $H$, Delot EC, et al. Next-generation mapping: a novel approach for detection of pathogenic structural variants with a potential utility in clinical diagnosis. Genome medicine. 2017;9(1):90.

28. Zhong J, Xie Y, Bhandari V, Chen G, Dang Y, Liao H, Zhang J, Lan D. Clinical and genetic characteristics of female dystrophinopathy carriers. Mol Med Rep. 2019;19(4):3035-44. https://doi.org/10.3892/mmr.2019.9982. Epub 2019 Feb 25.

29. Nota B, Hamilton EM, Sie D, Ozturk S, van Dooren SJ, Ojeda MR, Jakobs C, Christensen E, Kirk EP, Sykut-Cegielska J, et al. Novel cases of D-2hydroxyglutaric aciduria with IDH1 or IDH2 mosaic mutations identified by amplicon deep sequencing. J Med Genet. 2013;50(11):754-9.

30. Qin L, Wang J, Tian X, Yu H, Truong C, Mitchell JJ, Wierenga KJ, Craigen WJ, Zhang WW, Wong LC. Detection and quantification of mosaic mutations in disease genes by next-generation sequencing. $J$ Mol Diagn. 2016;18(3):446-53.

31. Dinh LT, Nguyen DH, Luong LH, Le PT, Le-Anh TP, Tran DQ, Tran TH, Bui TH, Van Ta T, Tran VK. Mosaicism in carrier of Duchenne muscular dystrophy mutation - implication for prenatal diagnosis. Taiwan J Obstet Gynecol. 2018;57(6):878-80.

32. Bakker $\mathrm{E}$, Veenema H Fau - Den Dunnen JT, Den Dunnen Jt Fau - van Broeckhoven C, van Broeckhoven C Fau - Grootscholten PM, Grootscholten Pm Fau - Bonten EJ, Bonten Ej Fau - van Ommen GJ, van Ommen Gj Fau Pearson PL, Pearson PL: Germinal mosaicism increases the recurrence risk for 'new' Duchenne muscular dystrophy mutations. (0022-2593 (Print)). J Med Genet. 1989;26(9):553-9. https://doi.org/10.1136/jmg.26.9.553.

33. Voit T, Neuen-Jacob E, Mahler V, Jauch A, Cremer M. Somatic mosaicism for a deletion of the dystrophin gene in a carrier of Becker muscular dystrophy. Eur J Pediatr. 1992;151(2):112-6.

34. Bushby K, Finkel R, Birnkrant DJ, Case LE, Clemens PR, Cripe L, Kaul A, Kinnett K, McDonald C, Pandya S, et al. Diagnosis and management of Duchenne muscular dystrophy, part 1: diagnosis, and pharmacological and psychosocial management. Lancet Neurol. 2010;9(1):77-93.

35. Nakamura A. Mutation-Based Therapeutic Strategies for Duchenne Muscular Dystrophy: From Genetic Diagnosis to Therapy. J Pers Med. 2019;9(1):16. https://doi.org/10.3390/jpm9010016

36. Nicolas A, Lucchetti-Miganeh C, Yaou RB, Kaplan JC, Chelly J, Leturcq F, Barloy-Hubler F, Le Rumeur E. Assessment of the structural and functional impact of in-frame mutations of the DMD gene, using the tools included in the eDystrophin online database. Orphanet J Rare Dis. 2012;7:45.

37. Spurney C, Shimizu R, Morgenroth LP, Kolski H, Gordish-Dressman H, Clemens PR, Investigators C. Cooperative international neuromuscular research group Duchenne natural history study demonstrates insufficient diagnosis and treatment of cardiomyopathy in Duchenne muscular dystrophy. Muscle Nerve. 2014;50(2):250-6.

38. Mah JK, Korngut L, Dykeman J, Day L, Pringsheim T, Jette N. A systematic review and meta-analysis on the epidemiology of Duchenne and Becker muscular dystrophy. Neuromuscul Disord. 2014;24(6):482-91.

39. Flanigan KM, von Niederhausern A, Dunn DM, Alder J, Mendell JR, Weiss RB. Rapid direct sequence analysis of the dystrophin gene. Am J Hum Genet. 2003;72(4):931-9.

40. Chen L, Ren J, Chen X, Chen K, Rao M, Zhang N, Yu W, Song J. A novel mutation of dystrophin in a Becker muscular dystrophy family with severe cardiac involvement: from genetics to clinicopathology. Cardiovasc Pathol. 2018:36(1879-1336 (Electronic)):64-70.

41. Pons R, Kekou K, Gkika A, Papadimas G, Vogiatzakis N, Svingou M, Papadopooulos C, Nikas I, Dinopoulos A, Youroukos S, et al. Single amino acid loss in the dystrophin protein associated with a mild clinical phenotype. Muscle Nerve. 2017;55(1):46-50.

42. Mohammed F, Elshafey A, Al-Balool H, Alaboud H, Al Ben Ali M, Baqer A, Bastaki L. Mutation spectrum analysis of Duchenne/Becker muscular dystrophy in 68 families in Kuwait: the era of personalized medicine. PLoS One. 2018;13(5):e0197205.

43. Beekman C, Janson AA, Baghat A, van Deutekom JC, Datson NA-O. Use of capillary Western immunoassay (Wes) for quantification of dystrophin levels in skeletal muscle of healthy controls and individuals with Becker and Duchenne muscular dystrophy. PLoS One. 2018;13(4):e0195850. eCollection 2018. https://doi.org/10.1371/journal.pone.0195850.

44. Wang DN, Wang ZQ, Yan L, He J, Lin MT, Chen WJ, Wang N. Clinical and mutational characteristics of Duchenne muscular dystrophy patients based on a comprehensive database in South China. Neuromuscul Disord. 2017; 27(8):715-22.

\section{Publisher's Note}

Springer Nature remains neutral with regard to jurisdictional claims in published maps and institutional affiliations.

Ready to submit your research? Choose BMC and benefit from:

- fast, convenient online submission

- thorough peer review by experienced researchers in your field

- rapid publication on acceptance

- support for research data, including large and complex data types

- gold Open Access which fosters wider collaboration and increased citations

- maximum visibility for your research: over $100 \mathrm{M}$ website views per year

At BMC, research is always in progress.

Learn more biomedcentral.com/submission 